\title{
PSS-FMEA: TOWARDS AN INTEGRATED FMEA METHOD TO SUPPORT THE DEVELOPMENT OF PRODUCT-SERVICE SYSTEMS IN SMES
}

\author{
Mahl, Tobias (1); \\ Köhler, Christian (1); \\ Arnold, Dominik (2); \\ Lins, Dominik (2); \\ Kuhlenkötter, Bernd (2) \\ 1: htw saar, Saarland University of Applied Sciences; \\ 2: Chair of Production Systems, Ruhr-Universität Bochum
}

\begin{abstract}
In industry, Failure Mode and Effects Analysis is an established quality tool for minimizing development risks in systems, products and processes. Nevertheless, the presented use case shows that the application of the FMEA method in the development of Product-Service Systems in a SME requires modifications to ensure that the special character of PSS is appropriately included and that risks can be adequately assessed and prioritized.
\end{abstract}

Keywords: Product-Service Systems (PSS), Risk management, Case study, FMEA, SME

\section{Contact:}

Köhler, Christian

htw saar - Saarland University of Applied Sciences

Business School

Germany

christian.koehler@htwsaar.de 


\section{MOTIVATION}

Industry 4.0 is a global trend that is changing industry by new forms of value creation and novel business models offering companies the opportunity to develop and market downstream services (Kagermann et al., 2013). Product-Service Systems (PSS) are one of these forms of additional value creation. In the B2B context Meier et al.(2010) define an industrial PSS as follows: "An Industrial Product-Service System is characterized by the integrated and mutually determined planning, development, provision and use of product and service shares including its immanent software components in B2B applications and represents a knowledge-intensive socio-technical system". Thus, the objective of a PSS is to deliver holistic solutions meeting specific customer needs by combining products and services.

Due to economic and ecological benefits, the implementation of PSS is an important trend around the globe. Especially in Germany it is proceeding faster than expected. A comparison of two studies about the implementation status of PSS from 2011 and 2015 prove this. In $201524.7 \%$ of the companies surveyed met the criteria of a PSS provider. This was a growth of approximately $10 \%$ compared to the year of 2011. (Bahrke and Kempermann, 2015)

The offering of a PSS can lead to better relationships with customers and can speed up innovation to keep up with customer demands (Tukker, 2004). This can also lead to competitive advantages in the market because it is harder to copy the integrated package of product and service compared to only selling a product (Baines et al., 2007). Often, this helps customers to concentrate on their core activities (Tukker, 2004) or customers get an increased value through highly customized solutions (Baines et al., 2007). Another reason for customers to adopt a PSS is that PSS are reducing risks for the customers, a benefit customers are willing to pay for (Reim et al., 2016).

Despite these benefits, PSS are mainly provided by companies with more than 250 employees and not by SMEs (Biege et al., 2013). A potential reason is that the change towards a PSS-oriented business model is a complex, demanding and risky change process. For those processes a strong consideration of risk management is demanded by ISO 9001:2015 (International Organization for Standardization, 2015). Therefore, risk mitigation has to be an important sub-process for the development and change towards a PSS-oriented business model.

This leads to the scope of this paper. Since risk reduction and the related risk shift to the provider are key selling points for PSS this paper addresses the topic of risk prevention in the PSS development process between the stages of concept development and detailed development (Haber and Fargnoli, 2017). The original idea was to support the risk assessment of newly developed PSS concept by the well-known failure mode and effect analysis (FMEA). During a test session it became obvious that the original FMEA method could not be applied to the case because the integrated character of a PSS (e.g. changes to the product can lead to problems in service provision) could not be assessed. Potential solution approaches found in a literature review did also not fit entirely for the evaluation and ranking of risks in PSS development. Therefore, this paper describes a case and modifications to the method of PSS-FMEA that give an answer to the following research question: How needs the FMEA method to be adjusted to become a useful tool in the PSS development process in SMEs?

To answer the question this contribution first introduces the theoretical background. Then the business case is introduced. Based on findings of the FMEA application in the case company adjustments to the method are presented. Finally, the results of the practical application are described in section 5 .

\section{THEORETICAL BACKGROUND}

\subsection{FMEA and Service-FMEA}

The aim of FMEA is to find and prioritise possible faults in systems, products, or processes and to minimise or avoid their effects. There are three different types of classical FMEA, first developed by the US military in 1940 and later adapted by the automotive and other industries: design FMEA, system FMEA and process FMEA (Da Silva and Carvalho, 2019). The realisation of FMEA starts with the identification of failure modes. In the next step possible causes, effects and hazards for each failure are listed. Then the failure needs to be evaluated. For the evaluation three factors are used. Severity (S) describes the consequences of the failure. Occurrence $(\mathrm{O})$ describes the likelihood for the failure to occur and detection (D) describes if the failure is easy to detect or not. Then the risk priority number (RPN) is calculated by multiplying the three factors. For failure modes with a high RPN measures are needed. The 
performance of the improved system is then monitored and re-evaluated after a reasonable period of time (Da Silva and Carvalho, 2019).

Service-FMEA is a special form of FMEA for the development of services. The procedure for the Service-FMEA is primarily the same as for the classic FMEA. The difference between services and products or processes is that when services are provided in direct customer contact, faults are immediately detected. Therefore, only the factors severity (S) and probability of occurrence (O) are assessed in the evaluation process for services (Geum et al., 2011).

\subsection{Literature review on FMEA application in the context of PSS}

To identify existing approaches, related to the usage of FMEA in the development of PSS, a systematic literature review has been carried out. The aim of the literature review was to find existing approaches that could be applied in the development of PSS in a SME. The literature study is based on the PRISMAStatement method (Moher et al., 2015), an established model in medicine for conducting meta-studies, which is also proposed for engineering design research (Lame, 2019). The literature research was conducted in the databases "Web of Science", "EBSCOhost" and "TEMA". Search phrases were used, which contain combinations of relevant search strings, such as "produ?t service syste*", "produ?t service", "PSS", "IPSS", "FMEA", "Failure Mode and Effects Analysis" and "Fehlermöglichkeits- und einflussanalyse". The procedure of the systematic literature research is shown schematically in Figure 1. The database search yielded only 20 hits in total. After the removal of duplicates, the titles and abstracts of the remaining 19 papers were reviewed. Thereof 15 papers were excluded because they did not address the desired topic. The assessment of the remaining papers did not lead to further exclusions.

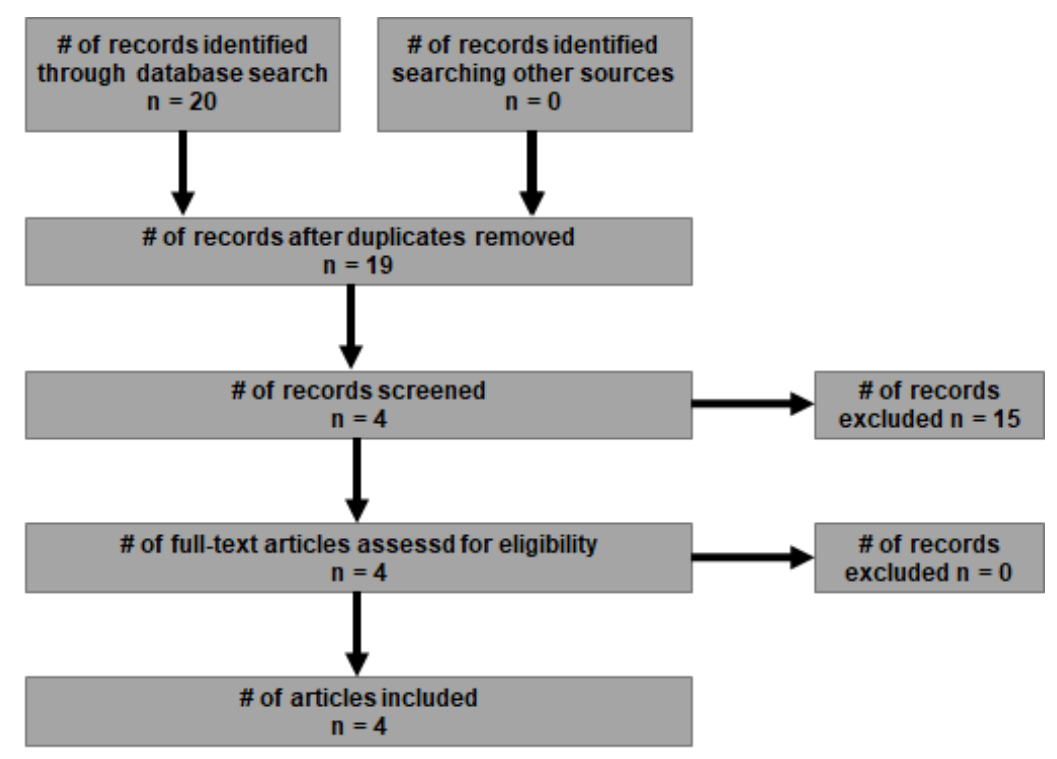

Figure 1. Systematic literature review process based on Lame (2019)

As there were only four relevant hits by the systematic literature research the "snowballing" method was used to extend the range of the research. With "snowballing" (Wohlin, 2014), all titles from the bibliography of the selected papers were checked (backward snowballing) as well as all the papers citing the selected paper (forward snowballing). This was carried out with all four papers found via the database search. Through snowballing one further title could be identified. All identified titles are listed in Table 1.

In all five papers the method FMEA is used in the development process for PSS. Köhler et al. (2007) combine the FMEA for products and the Service-FMEA into one integrated method to evaluate the entire delivery process of a PSS. This integrated FMEA begins with the decision whether the item to be evaluated is a service or a product/production process. When a service compoment is evaluated, no value is assigned to the detection (D) factor, as it is assumed that a service is performed in direct contact with the customer and therefore failures cannot occur without the customer being aware of them. Therefore, the risk priority number (RPN) for service processes is calculated by multiplying the factors severity (S) and occurrence $(\mathrm{O})$. Products or production processes are evaluated as usual. However, Köhler et al. added a fourth factor named reduction factor (R). It is added for both RPN calculations. As a special 
characteristic of PSS, this factor assesses measures that can reduce the negative effects when an error has occurred (e.g. annoyance of the customer).

Table 1. Results of the literature review

\begin{tabular}{|l|l|l|l|}
\hline Source & Author & Year & Title \\
\hline $\begin{array}{l}\text { Database } \\
\text { search }\end{array}$ & Köhler et al. & 2007 & $\begin{array}{l}\text { Leistungsbündel unter der Lupe. Integrierte FMEA für } \\
\text { Product-Service-Systems (PSS-FMEA) }\end{array}$ \\
\hline $\begin{array}{l}\text { Database } \\
\text { search }\end{array}$ & Zhang, Chu & 2010 & $\begin{array}{l}\text { A new approach for conceptual design of product and } \\
\text { maintenance }\end{array}$ \\
\hline $\begin{array}{l}\text { Database } \\
\text { search }\end{array}$ & Chiu et al. & 2018 & $\begin{array}{l}\text { An integrated product service system modelling } \\
\text { methodology with a case study of clothing industry. }\end{array}$ \\
\hline $\begin{array}{l}\text { Database } \\
\text { search }\end{array}$ & Kimita et al. & 2018 & $\begin{array}{l}\text { A failure analysis method for designing highly reliable } \\
\text { product-service systems }\end{array}$ \\
\hline Snowballing & Kimita et al. & 2020 & $\begin{array}{l}\text { Failure analysis method for enhancing circularity } \\
\text { through systems perspective }\end{array}$ \\
\hline
\end{tabular}

Zhang and Chu (2010) describe a design approach to meet the correct maintenance strategies with products. To achieve this, they are combining the method quality function deployment (QFD) and FMEA. Zhang and Chu use QFD to map customer requirements with engineering characteristics and then translate these into product related and maintenance related engineering characteristics which are then mapped with product modules and maintenance strategies. In the next step House-of-Quality is used to calculate the best combinations for product modules and maintenance strategies. Finally, a traditional FMEA is used to identify failure modes in the product concepts.

Chiu et al. (2018) propose a design concept to redesign and improve existing PSS. The redesign process starts with a customer survey among unsatisfied customers to identify potential failure modes in the PSS. These potential failure modes were analysed with importance-performance analysis (IPA) and weighted according to the customer feedback. Next the FMEA is used to evaluate and rank the failure modes according to their RPN. The calculated RPN will then be weighted with the factor from the IPA. Possible solutions are summarized in a service-product development matrix. To find the best solution grey relation analysis was carried out.

Kimita et al. (2018) are using FMEA in a concept to design highly reliable PSS. First, the relationships between customer requirements and functions and entities are shown with a "view model". Next, the PSS delivery process will be visualised with a service blueprint. Now FMEA is applied to the entities in the view model. An entity can be a product component or an actor in the PSS. The evaluation of the possible failure modes is carried out on a scale from 1 to 5 for detection and occurrence. The severity factor is calculated by using the method QFD to calculate the influence of a component's behaviour or actors' activities on the users' requirements. After applying the FMEA the improvements are applied to the service blueprint.

Kimita et al. (2020) propose an altered FMEA to enhance circularity through systems perspective. This is achieved by adding another column to the FMEA called "cause-effect-relationship". In this version of the FMEA the designers also consider if a failure mode influences another failure mode and calculate the "net cause or effect" for each failure mode. This value is calculated by using the Decision-Making Trial and Evaluation Laboratory (DEMATEL) method.

The literature review provided five possible options for the usage of FMEA in the context of PSS: one approach introducing a modified method and four approaches describing more or less complete development processes including the FMEA method. Since the requirements on development tools for SMEs differ from those of large companies (Peruzzini et al., 2014; Wiesner et al., 2017) it is concluded that the case company would only accept a modified FMEA that is an easy-to-use tool with clear recommendations for actions. Because the application of QFD, DEMATEL and large customer surveys do not meet the requirements of the SME, it was decided to apply the PSS-FMEA approach.

\section{CASE STUDY: DESCRIPTION AND EXPERIENCES}

The case company is a SME that offers anodizing of aluminium components to regional customers. Over the past years the company faced more and more problems in the anodizing business. The added value that the company contributes in comparison to the rest of the value chain is very low while the value of the components is typically very high. This results in a high risk for the company in case of damages. In 
addition, components are becoming increasingly complex, making anodizing more costly for the company. However, customers do not want to pay higher prices for this. Furthermore, due to lacking negotiation power with large customers the case company faces difficulties to enforce higher prices. The company is hence looking for new ways to create value for their customers with services to augment the range of offerings around the core anodizing business.

To achieve this goal the company decided to develop a PSS. The PSS should offer customers added value while simultaneously negating problems the company has with its current business model. The development process is based on Alam and Perry (2002) and started with a workshop to generate ideas for additional services. This workshop itself was structured based on the Design Thinking approach (Lewrick et al., 2018) and generated eight ideas. The workshop team evaluated the ideas and chose the best for further development. The next step in the development process was the creation of a service blueprint and the implementation of a requirements analysis.

The PSS idea is based on the implementation of a new enterprise resource planning software that the company is currently working on and is divided in two development stages. The new service gives customers in the first stage the opportunity to re-prioritise their order for an additional charge, so it is processed more quickly. In the second stage, which is to be implemented as soon as the first stage is running smoothly, the customer has the possibility to block production capacities of the company in exchange of a fee. According to the model of Tukker (2004) this new service in combination with the core product anodizing is a product-oriented PSS.

The next step in the development process of this PSS is the risk analysis. The development team decided to apply the FMEA method, because it is an established approach which is used worldwide to prevent risks early in the development phase of products and services (Da Silva and Carvalho, 2019). Special attention should be paid to the interaction of the product and service components or in the special case of the anodising company to the interaction between the existing operation processes and the new service aspects.

For the application of the PSS-FMEA as promised by Köhler et al. (2007) process steps from the service blueprint were added as items in the FMEA. Before evaluating a process step, a distinction was made between service processes and production processes. Production processes were evaluated with the factors $\mathrm{S}, \mathrm{D}$ and $\mathrm{O}$ on a scale from 1 to 10 as well as the reduction factor on a scale from $1 / \mathrm{S}$ to 1 . Service processes were evaluated with the factors $\mathrm{S}, \mathrm{O}$ and the reduction factor on the same scale. While carrying out the PSS-FMEA as described above, five methodical problems came up:

- The comparability of the RPN for products/production processes and service processes appeared as the first problem. Since the two process types are evaluated with a different number of factors, there is no inter-comparability between the RPN of both categories. Thus, no clear ranking of the failure modes could be established.

- Second, although the Service-FMEA rules out the possibility of failure detection, almost every evaluation of the service elements led to discussions whether the failure mode could be detected or not. As a matter of fact, not all service components are performed in direct contact with the customer and therefore failure detection and assessmeent is possible. Overall, doing this, would add a third type of RPN and amplify the problem of non-inter-comparable RPNs.

- Third, the detection problem described is more complex with regards to the assessment of the failure detection. It makes a difference whether an failure is detected early enough or too late in a subsequent process step. If the failure is detected immediately, the problem could still be solved. If the failure is discovered too late, the provision of the service is jeopardised or no longer possible. This problem of time dependency of failure discovery and the possibility of being able to react is not represented by the evaluation criteria.

- Fourth, the FMEA team tended to an extensive usage of the reduction factor on almost every failure mode detected. As a result, many additional risk reduction actions were proposed, some of which would have bypassed the original service with much additional operational effort and, furthermore, did not lead to real risk reduction.

- $\quad$ Fifth, the system concept of the PSS led to a further problem in the evaluation of possible failures. The behaviour of the customer becomes an additional cause of potential risks that cannot be excluded anymore. Interestingly, there are typically known "errors" caused by the customers that were no risk for the "old" process of the case company but would make the delivery of the "new" PSS impossible. So, potential errors caused by the customers need to be identified. 


\section{ADJUSTMENTS TO THE PSS-FMEA APPROACH}

As mentioned before five problem areas were identified and thus build the basis for the further development of the PSS-FMEA approach.

\subsection{Comparability of risk priority numbers}

The reason for the lack of comparability between the RPN for the product or process components and the service components is the different range of possible valuation results. Multiplying the three factors for the valuation of product and process components yields numerical values between 1 and 1000. For service components, only the numerical values between 1 and 100 are possible due to the two valuation factors. As a result, the risk priority numbers of service components always appear lower in comparison to product or process components, i.e. that risks can easily be overlooked: The risk priority figure of 80 is exemplary here. For a product or process component this means a negligible risk. In the case of a service component, 80 is an indication of a high failure risk.

Several solution approaches can be used to solve this problem:

1. no direct comparison between service and product/process components:

As a consequence, the risks need to be assessed separately using different target values. This, for example, could be done using two risk lists. However, this would lead to a loss of both, the clarity of the recommended action and the system idea. An ambiguous suggestion for action is not recommended, especially in the case of SMEs, as it makes the FMEA application more complicated. Here it should be considered in particular that in SMEs, in contrast to large companies, often no FMEA method specialists are kept available to support the operative areas. Therefore, this approach will therefore not be further pursued.

2. Instead of absolute risk priority numbers, percentages are used or an indexation is applied:

The advantage of this approach is the possiblity of direct comparability. The calculation could either be done by multiplying the risk priority number of the service component by 10 or by dividing the risk priority numbers of all components by the calculated maximum of the RPN (i.e. service components by 100 , product/process components by 1000). The percentage approach would also require the target value for the optimisation limit to be adjusted. For example, a risk priority number of 125 would become a value of $12.5 \%$. This approach seems feasible at first sight. However, it must be noted that the assessment of the service component could be distorted in relative terms. Mathematically, this is equivalent to an evaluation of the failure detection with a factor of 10 .

3. Introduction of the assessment of the failure detection for the service component:

Contrary to the established practice of Service-FMEA, the case of a PSS-FMEA could integrate a failure detection assessment. This is because certain parts of an integrated service component also occur behind the so-called "line of visibility". This means that in certain cases errors in a service component could still be detected. Only if they occur before the line of visibility of the service, they would no longer be detected, which is equivalent to a factor of 10. This would level the RPNs of the service components to a realistic level. To implement this solution, evaluation criteria for the failure detection would need to be defined. The solution is thus classified as promising.

4. Applying the risk priority logic of the new AIAG FMEA standard:

The new AIAG FMEA standard (Automotive Industry Action Group, 2019) replaces the risk priority number by a complex system for the determination of task priorities. This solution could function as a workaround to this problem. However, for the intended usage of the tool in SMEs and under the consideration that most of them are not part of the automotive industry this approach appears to be too complex and, thus, will not be pursued further.

The second and third solution approaches seem to be the most promising. Under consideration of the findings of the following section, the authors have decided to pursue solution approach three further.

\subsection{Assessment criteria for a time-differentiated failure detection}

During the assessment of the service components the FMEA team members discussed quite often whether it is possible to detect a failure mode inhouse and thus wanted to assess the probability of detection. Although this was excluded in the original PSS- and Service-FMEA logics there are some practical considerations why this could make sense, nevertheless. In the case of an early and inhouse failure detection there might be enough time left to compensate the failure (with additional efforts) or 
even heal it. The precondition for this case is that the failure detection must take place with a sufficient time buffer before the service reaches the line of visibility. These considerations can act as criteria for the failure detection assessment of a service component (see Table 2), that is partly inspired by the assessment criteria of the new AIAG FMEA guideline (Automotive Industry Action Group, 2019).

Table 2. Assessment criteria for the detection of a service component

\begin{tabular}{|l|l|}
\hline Assessment & Criteria \\
\hline $\mathbf{1 0}$ & $\begin{array}{l}\text { No detection possible at all or failure detection behind the line of visibility and } \\
\text { detection by customer is unavoidable }\end{array}$ \\
\hline $\mathbf{9}$ & $\begin{array}{l}\text { Failure detection behind the line of visibility but detection by service provider is } \\
\text { still likely } \\
\text { Failure detection behind the line of visibility but detection by service provider is } \\
\text { very likely }\end{array}$ \\
\hline $\mathbf{8}$ & Failure detection before the line of visibility but time too little to react inhouse \\
\hline $\mathbf{7}$ & $\mathbf{6}$ \\
$\mathbf{5}$ & $\begin{array}{l}\text { Failure detection before the line of visibility, still enough time left to heal the } \\
\text { failure }\end{array}$ \\
\hline $\mathbf{3}$ & $\begin{array}{l}\text { Failure detection before the line of visibility with enough time to completely debug } \\
\text { the failure }\end{array}$ \\
\hline $\mathbf{2}$ & \\
\hline
\end{tabular}

\subsection{Conditions for the use of the reduction factor}

In principle, the reduction factor was considered a useful extension of the FMEA methodology in the PSS context. This is especially because it allows to consider PSS characteristics that can limit the negative effects of a failure mode. At the same time, the use case has shown that without regulation the reduction factor was used inflationary. This leads to an inadmissible reduction of the risk potential on one side, but on the other side it leads to inefficiencies in the company, because risks are mitigated by additional operational expenditure. Therefore, the following rule must be respected when applying the reduction factor:

The reduction factor may only be applied in the risk assessment when all technically, organisationally, and personally feasible and economically viable measures to prevent and detect the failure have been exhausted.

In the method this is anchored by a distinction between an RPN1 (traditional, without application of the reduction factor) and an RPN2 (modified RPN with additional application of the reduction factor).

\subsection{Integration of failure modes caused by the user}

When delivering a service, a direct interaction with users is unavoidable. With regards to robustness in the user-centred development of a PSS, likely failure modes caused by the users have to be considered. Thus the traditional thinking considering all input factors as good quality (Robert Bosch GmbH, 2012) is no more applicable to PSS-FMEA in the context of service components.

\subsection{Adjusted PSS-FMEA sheet and process description}

In summary, the outlined adjustments lead to a slightly modified process of the PSS-FMEA and to an adaptation of the PSS-FMEA sheet. The new process is shown in Figure 2 and the sheet in Figure 3. So, the adjusted PSS-FMEA can be used for risk assessment after different development steps (e.g. in the concept development phase according to Haber and Fargnoli (2017) to assess risks of the identified product and service elements). To identify relevant PSS elements, first a service blueprint visualising the entire delivery process including all production and service process was developed. Subsequently, the project team selected the critical sub-processes for the provision of the PSS by means of dot-voting. 


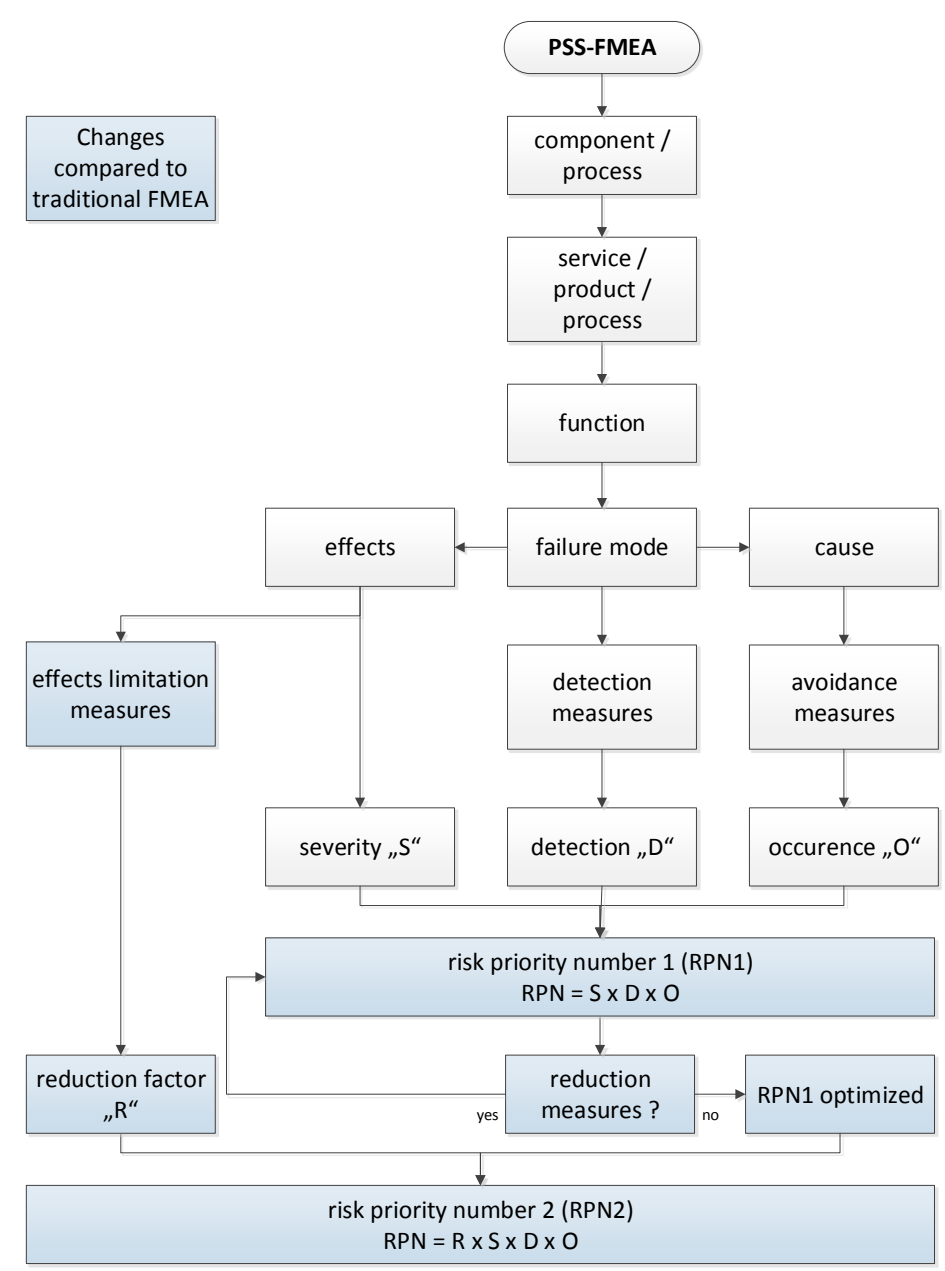

Figure 2. PSS-FMEA process

\section{EFFECTS OF THE PSS-FMEA ADJUSTMENTS}

The adjustments on the PSS-FMEA approach described in section 4 have been applied to the results of the FMEA described in section 3 to validate the changes. The results are shown in Figure 3. First, the evaluation sheet for FMEA was adapted to the adjusted method. Previously, the detection measures and the detection factor were greyed out when a service process was evaluated and a RPN was calculated with only 2 factors. Now the RPN is determined in two steps: First, all potential errors for the process steps that need to be evaluated are listed. Then the potential causes and effects are described, as well as the prevention and detection measures. This is followed by an assessment of severity $(\mathrm{S})$, occurrence $(\mathrm{O})$ and detection (D). After, the RPN1 can be calculated. Subsequently, reduction measures can be described and evaluated for the most important processes in accordance with the rule described in Chapter 4.3. If no reduction measures are applied, a factor of 1 is used. Finally, the RPN2 can be calculated and the failure modes be ranked.

The differences between the original assessment and the improved assessment are illustrated by two examples in Figure 3. The two potential failures relate to the use of the service platform by the customer. In the first example the platform is offline and therefore cannot be used by the customer. As a preventive measure, the use of an external service provider with appropriate measures was suggested and, in line with the approach initially used, no detection measure was proposed. As a reduction measure, it should be offered that the customer can call and book the service by phone. A RPN of 7 was calculated. Under the new evaluation procedure, a monitoring function was conceived as a detection measure and a reevaluation was carried out. It was also decided not to offer a reduction measure in this case. This leads to a RPN2 of 42. In the second example, the customer cannot access the service platform because the website is blocked by the customer's IT department. As a prevention measure, a detailed pre-test of the service was suggested and as a reduction measure the customer should be able to book the service again by phone, should be informed about the problem and asked for clarification with the IT department. 
According to the new assessment scheme, the probability of detection was assessed at 10 , as there are no detection measures for this case. However, the described reduction measure makes sense in this case, resulting in a RPN2 of 70.

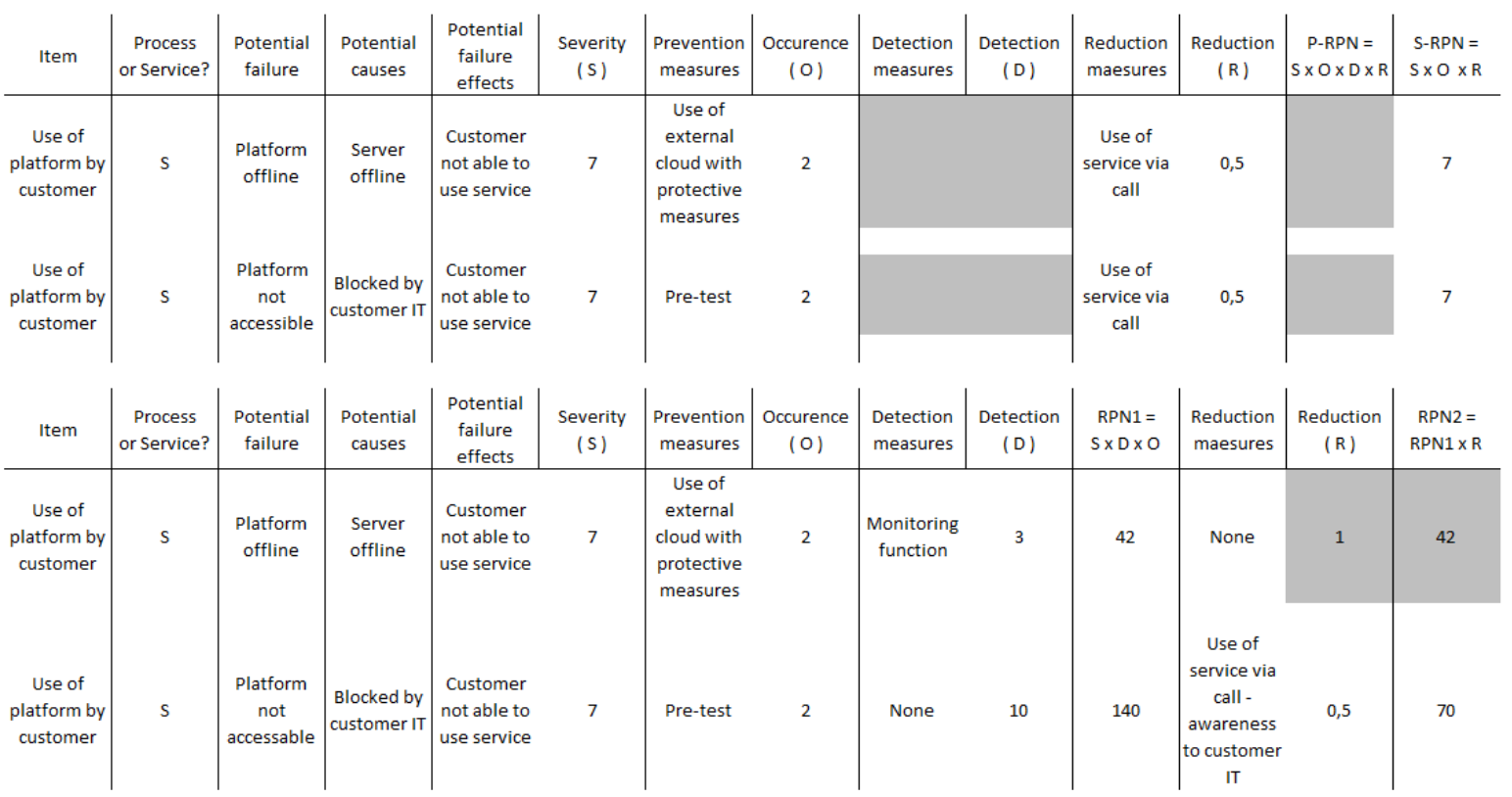

Figure 3. FMEA-evaluation sheet before (top) and after (bottom) the modifications

The application of the modifications to the results of the original PSS-FMEA according to Köhler et al. (2007) shows that the modified version is more consistent in the risk application and supports both the effectiveness of the PSS and the efficiency of its provider. The comparable RPN for product/production and service processes enables a fast and straight forward prioritisation of the discovered risks. Furthermore, the assessment of the detection factor is accelerated by the clear and adapted criteria.

\section{CONCLUSION}

This contribution describes the further development of a modified FMEA tool to support the development of PSS based on insights from the application in a case company. Applied again in the case, the modified method was found to be effective and supporting in the process of PSS development. In addition, the case study has shown that risk assessment in the PSS development process is a crucial process step that should not be omitted, as the results of the FMEA in the testing company contained several failure modes that were not a problem in the standard process, but are now considered very critical for the successful delivery of the new service. The presented modifications allow to use a familiar tool in the development of complex PSS. This can help to overcome the barriers in the transformation to PSS-supported business models especially in SMEs. So far, the modified PSS-FMEA has only been tested in one company in one scenario. Further tests will therefore be carried out with other scenarios and in other companies to verify the validity of the method.

\section{ACKNOWLEDGMENT}

The project ABILITY is financed with funding provided by the German Federal Ministry of Education and Research and the European Social Fund under the "Future of work" programme.

\section{REFERENCES}

Alam, I. and Perry, C. (2002), “A customer-oriented new service development process”, Journal of Services Marketing, Vol. 16 No. 6, pp. 515-534.

Automotive Industry Action Group (2019), FMEA Handbook: Failure Mode and Effects Analysis.

Bahrke, M. and Kempermann, H. (2015), Hybride Geschäftsmodelle als Lösungsanbieter zum Erfolg: Eine vbw Studie, erstellt vom Institut der deutschen Wirtschaft Consult GmbH Stand: Mai 2015, München.

Baines, T.S., Lightfoot, H.W., Evans, S., Neely, A., Greenough, R., Peppard, J., Roy, R., Shehab, E., Braganza, A., Tiwari, A., Alcock, J.R., Angus, J.P., Bastl, M., Cousens, A., Irving, P., Johnson, M., Kingston, J., Lockett, H., 
Martinez, V., Michele, P., Tranfield, D., Walton, I.M. and Wilson, H. (2007), "State-of-the-art in productservice systems", Proceedings of the Institution of Mechanical Engineers, Part B: Journal of Engineering Manufacture, Vol. 221 No. 10, pp. 1543-1552.

Biege, S., Schröter, M., Gandenberger, C., Buschak, D., Weißfloch, U., Schlummer, M., Jäger, A. and Merk, S. (2013), Chancen für die nachhaltige Entwicklung durch neue hybride Wertschöpfungskonzepte: Abschlussbericht des Projekts "HyWert”, ISI-Schriftenreihe Innovationspotenziale, Fraunhofer, Stuttgart.

Chiu, M.-C., Chu, C.-Y. and Chen, C.-C. (2018), "An integrated product service system modelling methodology with a case study of clothing industry”, International Journal of Production Research, Vol. 56 No. 6, pp. 2388-2409.

Da Silva, R.F. and Carvalho, M.A. de (2019), “Anticipatory Failure Determination (AFD) for Product Reliability Analysis: A Comparison Between AFD and Failure Mode and Effects Analysis (FMEA) for Identifying Potential Failure Modes", in Chechurin, L. and Collan, M. (Eds.), Advances in Systematic Creativity: Creating and Managing Innovations, Springer International Publishing, Cham, pp. 181-200.

Geum, Y., Shin, J. and Park, Y. (2011), "FMEA-based portfolio approach to service productivity improvement", The Service Industries Journal, Vol. 31 No. 11, pp. 1825-1847.

Haber, N. and Fargnoli, M. (2017), "Designing Product-Service Systems: A Review Towards A Unified Approach”, in 7th International Conference on Industrial Engineering and Operations Management 2017. Rabat, Morocco, 11-13 April 2017, Curran Associates Inc, Red Hook, NY, pp. 817-837.

International Organization for Standardization (2015), ISO 9001:2015: Quality management systems Requirements, 5th ed., Geneva, Switzerland.

Kagermann, H., Wahlster, W. and Helbig, J. (2013), Recommendations for implementing the strategic initiative INDUSTRIE 4.0: Securing the future of German manufacturing industry, Final report of the Industrie 4.0 Working Group, Frankfurt, available at: https://en.acatech.de/publication/recommendations-for-implementingthe-strategic-initiative-industrie-4-0-final-report-of-the-industrie-4-0-working-group/.

Kimita, K., Brambila-Macias, S.A., Tillman, A.-M. and Sakao, T. (2020), "Failure analysis method for enhancing circularity through systems perspective", Journal of Industrial Ecology, pp. 1-19.

Kimita, K., Sakao, T. and Shimomura, Y. (2018), "A failure analysis method for designing highly reliable productservice systems", Research in Engineering Design, Vol. 29 No. 2, pp. 143-160.

Köhler, C., Conrad, J., Wanke, S. and Weber, C. (2007), "Leistungsbündel unter der Lupe. Integrierte FMEA für Product-Service-Systems (PSS-FMEA)”, QZ - Qualität und Zuverlässigkeit, Vol. 52 No. 11, pp. 86-87.

Lame, G. (2019), "Systematic literature reviews: an introduction”, paper presented at ICED2019, 05.-08 August, Delft, Niederlande.

Lewrick, M., Link, P. and Leifer, L. (2018), The design thinking playbook: Mindful digital transformation of teams, products, services, businesses and ecosystems.

Meier, H., Roy, R. and Seliger, G. (2010), "Industrial Product-Service Systems_-IPS 2", CIRP Annals, Vol. 59 No. 2, pp. 607-627.

Moher, D., Shamseer, L., Clarke, M., Ghersi, D., Liberati, A., Petticrew, M., Shekelle, P. and Stewart, L.A. (2015), "Preferred reporting items for systematic review and meta-analysis protocols (PRISMA-P) 2015 statement", Systematic Reviews, Vol. 4 No. 1, p. 1.

Peruzzini, M., Marilungo, E. and Germani, M. (2014), "Functional and Ecosystem Requirements to Design Sustainable Product-Service", Advances in Transdisciplinary Engineering, Vol. 1, pp. 768-777.

Reim, W., Parida, V. and Sjödin, D.R. (2016), "Risk management for product-service system operation", International Journal of Operations \& Production Management, Vol. 36 No. 6, pp. 665-686.

Robert Bosch GmbH (2012), 14. Failure Mode and Effects Analysis FMEA: Quality Management in the Bosch Group, available at:

https://assets.bosch.com/media/global/bosch_group/purchasing_and_logistics/information_for_business_partn ers/downloads/quality_docs/general_regulations/bosch_publications/booklet-no14-failure-mode-and-effectsanalysis_EN.pdf.

Tukker, A. (2004), "Eight types of product-service system: eight ways to sustainability? Experiences from SusProNet", Business Strategy and the Environment, Vol. 13 No. 4, pp. 246-260.

Wiesner, S., Nilsson, S. and Thoben, K.-D. (2017), "Integrating requirements engineering for different domains in system development. Lessons learnt from industrial SME cases".

Wohlin, C. (2014), "Guidelines for snowballing in systematic literature studies and a replication in software engineering", in Shepperd, M., Hall, T. and Myrtveit, I. (Eds.), Proceedings of the 18th International Conference on Evaluation and Assessment in Software Engineering - EASE ‘14, 13.05.2014 - 14.05.2014, London, England, United Kingdom, ACM Press, New York, New York, USA, pp. 1-10.

Zhang, Z. and Chu, X. (2010), "A new approach for conceptual design of product and maintenance”, International Journal of Computer Integrated Manufacturing, Vol. 23 No. 7, pp. 603-618. 